\title{
Mathematical knowledge for teaching: adding to the description through a study of probability in practice
}

\author{
Mercy Kazima and Jill Adler \\ Marang Centre for Mathematics and Science Education, University of the Witwatersrand \\ mkazima@chanco.unima.mw and adlerj@educ.wits.ac.za
}

In their description of the mathematical work of teaching, Ball, Bass \& Hill (2004) describe the mathematical problem solving that teachers do as they go about their work. In this paper we add to this description through our study of teaching of probability in a grade 8 multilingual classroom in South Africa. We use instances of teaching to highlight the mathematical problem solving that teachers might face as they work with learners' ideas, both expected and unexpected. We discuss the restructuring of tasks as an inevitable feature of teachers' work, and argue that in addition to scaling up or scaling down of the task as Ball et al. (2004) describe, restructuring can also entail shifting the mathematical outcomes from those intended. We also point out how well known issues in mathematics education, for example working with learners' everyday knowledge, and the languages they bring to class, are highlighted by the context of probability, enabling additional insights into the mathematical work of teaching.

\section{Introduction}

What teachers need to know and know how to do, mathematically, to teach mathematics well has come into focus in mathematics education research and practice in recent years (e.g. Ma, 1999; Ball \& Bass, 2000; Ball, Bass \& Hill, 2004). Ball and her colleagues have produced helpful descriptions of mathematical knowledge for teaching (elaborated later in the paper) based on an in-depth study of mathematical practices in a particular elementary school classroom in the United States. Our goal in this paper ${ }^{1}$ is to add to this description, drawing from instances in a particular South African secondary classroom, one where an experienced teacher tackles a new topic in the curriculum, in this case, probability. In contexts of change, and ventures into different practices, we can and do confront moments of breakdown or disturbance that simultaneously open up opportunities for learning. We discuss three such moments in the teaching of probability in a grade 8 class in a South African township, each of which provides a window onto mathematical demands of teaching, and so opportunities for elaborating their description.

1 This paper forms part of a wider research project on Mathematical Knowledge for Teaching, directed by Jill Adler, at the University of the Witwatersrand. This material is based upon work supported by the National Research Foundation under Grant number 2053525. Any opinion, findings and conclusions or recommendations expressed in this material are those of the author(s) and do not necessarily reflect the views of the National Research Foundation.

\section{Mathematical knowledge for teaching (MKfT)}

The idea that there is specialised knowledge used in and for teaching is not new; it has been discussed, debated and researched for at least two decades now. Shulman's seminal work (Shulman, 1986; 1987) challenged George Bernard Shaw's "He who can does, He who cannot teaches" by pointing out that teaching entails more than simply knowing the subject matter. From his study, Shulman concludes that besides content knowledge and curricular knowledge, teachers need a third kind of knowledge which he calls 'pedagogical content knowledge' (PCK). He suggests that PCK "goes beyond knowledge of the subject matter per se to the dimension of subject matter knowledge for teaching" (1986: 9). He argues that teachers need to know and understand more of their subject than other users of the subject content because teaching entails transformation of knowledge into a form that learners can comprehend. He therefore suggests that the expression should be "Those who can do, Those who understand teach" because "the ultimate test of understanding rests on the ability to transform one's knowledge into teaching" (Shulman, 1986: 14).

There are convincing accounts of contestation over specialised knowledge for teaching, long predating Shulman (see, for example, Bullough, 2001, for an interesting history). Shulman's contribution, however, was to name PCK, and so spark a great deal of focused research. In the past two decades, many educators have elaborated the notion of pedagogical content knowledge through empirical 
study. Mathematics educators who have worked in this field include Marks (1992), Even (1990), Ma (1999), Ball et al. (2004) and Brodie (2004). ${ }^{2}$ Among these researchers, there seems to be agreement that teachers need a special kind of mathematical knowledge for teaching in order to teach well. Although researchers have not yet come to a consensus as to what exactly comprises MKfT, there is support for the notion coined by Ball and colleagues (Ball \& Bass, 2000; Ball, Lubienski \& Mewborn, 2001) that for teachers to teach mathematics well, they need to be able to unpack or decompress the mathematics they know and have learned, so as to be able to make it accessible to learners. In other words, teachers need not only know how to do mathematics, but they should also know how to use the mathematics in practice i.e. in and for teaching (Adler, 2005). ${ }^{3}$

Some researchers, drawing on Shulman's work, have attempted to identify and describe the knowledge required by teachers in order to teach a specific mathematics content area. For example, Marks (1992) worked on 'equivalent fractions'; Even (1990) and Sanchez \& Llinares (2003) have worked on 'functions'; Stacey, Helme, Steinle, Baturo, Irwin \& Bana (2003) have worked on 'decimal numeration'; and a large study is currently underway on 'knowledge for algebra teaching' (KAT) (Ferrini-Mundy, Senk \& McCrory, 2005). The researchers' findings support Shulman (1986, 1987) since they identified elements of the specialised mathematical knowledge that teachers need if they are to teach the specific mathematical content well. Through their topic specific focus, these studies add to the general discussion of PCK. Even (1990), for example, brings the notion of 'strength of the concept' - knowledge about the connectedness of a concept to other mathematical concepts at the same level and beyond, as an important part of PCK. The research reported here is similar to these topic focused studies in that it focuses on the topic of probability. As already mentioned, it adds to the field through a study not only of a different mathematical topic, but one being taught as a new

\footnotetext{
${ }^{2}$ We note with interest here, the July 2005 volume of Education Studies in Mathematics which is entirely focused on research in France and an elaboration of the theory of didactical situations. One paper refers to PCK, indicating additional engagement with this issue. See ESM volume 59, 2005, and particularly the paper by Margolinas et al.

3 In their recent work, Hill \& Ball (2004) have elaborated this specialised knowledge, calling it specialised content knowledge (SCK), and distinguish it from what they call common content knowledge (CCK). The later is the kind of mathematics a layperson would know (e.g. being able to multiply). SCK in contrast involves a great deal more.
}

topic area in the school curriculum. Like the studies above, the specificity of probability and its introduction into the curriculum, might bring additional aspects of MKfT to the fore.

\section{The significance of probability}

The selection of probability as a topic of study of the specialised knowledge it requires in teaching has significance beyond it being new in the curriculum. In the teaching (and learning) of probability, issues of everyday knowledge and language come to the fore. Neither of these areas are new to mathematics education and so the work of teaching. Our concern and interest is whether the specificity of probability brings these to light in new or different ways, and in ways that have implications for elaborating the notion of MKfT.

Probabilities are experienced in everyday life. Learners thus bring everyday knowledge and experience of probability and everyday use of probability language to their school learning ('everyday concepts' in Vygotskian terms (Vygotsky, 1978)). Intuitive knowledge of probability and how it is expressed informally can be misleading as the learner confronts formal probability concepts and meanings in class. In general, many aspects of probability are counterintuitive (Kvatinsky \& Even, 2002). For example, after tossing a coin four times and getting four heads, many would think the fifth toss is more likely to turn out tails because 'it is due'. Everyday experiences of coin tossing do not include necessary understanding of the actual (mathematical) independence of each toss. In addition words used in probability and English (e.g. likely) also carry everyday meanings for learners, meanings that can be constraining as well as enabling of learners' grasping its mathematical meaning, and more so when learners are studying in a language that is not their main language (Kazima, 2006). This has particular significance in contexts of cultural and linguistic diversity. Hence the significance of a study of MKfT probability in the South African context.

Probability is a relatively new topic in many countries' curricula. In South Africa, what is interesting is that probability was introduced as a topic of study in mathematics for the first time in the senior phase (grades 7-9) in 1992 (Laridon, 1995). Despite this being a decade ago, it has been possible for teachers in these middle years to omit this topic, and focus instead on number, algebra and geometry. It is in the more recent past, and the introduction of what is called Curriculum 2005, that data handling has been included as a required 


\section{Mathematical knowledge for teaching: adding to the description \\ through a study of probability in practice}

outcome. All schools now face Common Tasks of Assessment for Grade 9 (see DoE, 2004, for example), and these include assessment of probability concepts and skills. When experienced teachers are faced with a new topic, a crucial resource in their teaching - their own prior teaching experience of the topic (and so what to expect in terms of what learners find easy or difficult about the topic, what activities work well, and what misconceptions arise among learners) is not readily available.

Of course, research in the field has reported on these aspects of teaching probability. The question and challenge is whether and how teachers draw on these as resources in their teaching, and if not, why not. Recent research focused on the resources drawn on by an experienced teacher teaching functions in grade 10 confirms what is often claimed: that research in mathematics education is typically not used by teachers in their day to day work (Pillay, 2006). As a case study, there are significant dangers in any generalising from this observation. Rather, it presents the field with a dimension of the challenges facing the introduction of new topics in the curriculum, which often do have a research base to enable such challenges.

In this paper we share instances from an experienced teacher teaching probability for the first time in grade 8 . Each instance illuminates an aspect of teaching probability in particular, and provides for specific elaboration of more general descriptions of 'mathematical knowledge for teaching' (MKfT) (Adler, 2005).

\section{Research on probability in South African and elsewhere}

While a study of the knowing and doing entailed in the teaching of probability has not been done, there are studies both in South Africa and elsewhere that have explored learners' understanding of probability concepts. Laridon (1995) carried out such research in South Africa. His sample comprised of 870 learners, 14-15 years old, from 14 schools in the Witwatersrand and Transkei areas. He gave the learners a pre-test which contained items adapted from a comprehensive study done in the United Kingdom by Green (1989). Out of the 870 learners, 360 took the test again as a post-test after tuition on probability. Laridon reports that learners' responses to the questionnaire were by and large similar to those obtained by Green from learners in the UK. The results revealed misconceptions among the South African learners, for example, that chance events are equally likely. This misconception, known as the equiprobability bias (Lecoutre, 1992), has also been observed by other researchers, for example, Canizares and Batanero (1998) and Li \& PereiraMendoza (2002) (referred to in Watson, 2005). Laridon (1995) further reports that tuition did not significantly improve learners' performance. He concluded that learners assimilate the formal learning of probability into their intuitive or experiential knowledge. The formal tuition that was offered to learners in the implementation of the South African curriculum had little effect on the learners' probabilistic thinking. In his words "this could indicate that the teaching was not all that effective in developing understanding of probability concepts above that generally attained by these subjects through their everyday experience" (Laridon, 1995: 26).

Laridon, however, does not explain the kind of tuition that was offered, for example, whether or not the teachers addressed the contradictions between everyday and formal probability concepts, or the misconceptions that were revealed in the pre-test. Therefore, his conclusion about the effects of instruction needs to be treated with circumspection, particularly in the light of findings from research done elsewhere, e.g. Fischbein \& Gazit (1984), Fischbein, Nello \& Marino (1991) and Saenz (1998). Fischbein et al. investigated the effect of instruction on children's probabilistic thinking and found that it made a significant difference to performance of children nine years and older. These researchers reported that after formal instruction that was specifically designed by themselves, the children were able to evaluate chance successfully. In general they were able to "operate correctly with the concept of probability" (Fischbein \& Gazit, 1984: 91). Similarly, Saenz (1998) conducted a teaching experiment on 14-15 year-old Spanish students. The teaching was designed to confront students' previous misconceptions. Saenz found that the teaching significantly improved performance of the students.

The difference between these studies and Laridon's could be that Laridon's study was not conducted on learners who had been part of design experiments involving planned teaching of probability. Laridon's study can then be interpreted as reflecting on the ground realities of what transpires in probability classrooms where there has not been any research or professional development intervention into the teaching. Laridon's finding that the teaching of probability 
made little difference to learners' understanding of formal probability should then be of concern to mathematics educators, and raises the question of whether and how, and then why it is that the teaching of probability does not appear to improve learners' thinking?

We have also suggested above, that despite probability being a curriculum topic, until recently, it was not required and often not taught. And so Laridon's results can be re-interpreted in this light. In addition, the above contradictory research findings raise theoretical questions about context and competence. There are compelling arguments that learners' responses to mathematical tasks embedded in everyday contexts can depend on 'where' learners situate themselves (Saljo \& Wyndhamn, 1993). If learners' interpretation of the problem is an everyday interpretation, then their intuitions can be expected to dominate. If learners situated themselves in the mathematics classroom, however, they are likely to interpret the problem in more formal and mathematical ways. These are interesting and challenging issues for teachers in the context of teaching probability. And so our specific focus here and what it might illuminate is: How is probability taught when teachers tackle this new topic area? What can we learn from this that points to important aspects of knowing about probability in the context of teaching, and so potentially improve the teaching of probability?

\section{The current South African curriculum and focus of this study}

The Revised National Curriculum Statement for Mathematics in South Africa (DoE, 2001) suggests the introduction of probability in the senior phase (grades 7-9). The curriculum states that in this phase the study of probability should focus on the certain and uncertain nature of particular events. Furthermore, the teaching should highlight the uncertainty, randomness and independence of outcomes of single trials, and later compare with predictable outcomes over a large number of such trials. The curriculum further suggests that through experimentation and analysis of situations, learners should come to know the difference between experimental and theoretical probability as well as understand the relationship between the two (DoE, 2001).

What the emphasis here reveals is that even in this initial introduction to probability in secondary school, it is relatively concept heavy. In other words, there is considerable conceptual work that the teacher will need to do to enable meaning of probability to develop in learners. Like all concepts, these probability concepts are carried in language, and most are in use in the everyday, or what others have called 'ordinary English' (see, for example, Pimm, 1987). Within mathematics, each of these terms comes to have very specific mathematical meaning(s), meanings that may or may not resonate with the everyday uses of these terms.

What mathematics do teachers need to know and be able to do in practice in order to teach probability in the senior phase? To help answer this question, the study from which this paper is drawn explored three inter-related questions (i) What aspects of probability are encoded in curriculum documents? (ii) What mathematical 'problem solving' do teachers face as they go about teaching probability in their classroom? (iii) What knowledge resources do teachers draw on as they do what they do? In this paper, we focus on the second question, and report on some interesting problem solving incidents of a particular teacher as he introduced and taught probability for the first time to grade 8 learners in a school in South Africa.

Adler (2005), following Ball \& Bass (2000), describes mathematics teaching as involving particular kinds of problem solving - problem solving that has mathematical entailments. In other words, teachers confront problems of teaching as they go about their work, the 'solving' (or action) of which requires mathematical thinking in action, in the practice of teaching. We argue that (a) engaging with learners in classroom practice necessarily entails restructuring of tasks, with important mathematical entailments for the teacher in this in-the-act problem solving, and (b) the teaching of probability, precisely because of its conceptual base, and its use of mathematical English, entails engaging with learners' everyday knowledge and meanings. As we develop our arguments, we simultaneously elaborate elements of the mathematical problem solving teachers do. This, in turn, provides for further description of and insight into MKfT.

\section{Theoretical orientation and analytic framework}

The theoretical underpinning of the study is that mathematical knowledge for teaching is situated in the practice of teaching (Adler \& Davis, 2006; Ball \& Bass, 2000; Ball et al., 2004). Therefore, to study it entails an analysis of curriculum in both documentation and practice. In studying teaching, the study draws on Ball et al. (2004) who suggest 


\section{Mathematical knowledge for teaching: adding to the description through a study of probability in practice}

eight types of problem solving that mathematics teachers do as they go about their work. These are:

-Design mathematically accurate explanations that are comprehensible and useful for students

- Use mathematically appropriate and comprehensible definitions

- Represent ideas carefully, mapping between a physical or graphical model, the symbolic notation, and the operation or process

-Interpret and make mathematical and pedagogical judgements about students' questions, solutions, problems, and insights (both predictable and unusual)

- Be able to respond productively to students' mathematical questions and curiosities

- Make judgements about the mathematical quality of instructional materials and modify as necessary

- Be able to pose good questions and problems that are productive for students' learning

- Assess students' mathematics learning and take next steps.

Ball et al. (2004: 59)

We have condensed these into six, as follows: Definitions, Explanations, Representations, Working with learners' ideas, Restructuring tasks, and Questioning. There were two inter-related reasons for this condensing. Firstly, in our view, some of the above aspects are overlapping. For example, "interpret and make mathematical and pedagogical judgements about students' questions, solutions, problems, and insights", "be able to respond productively to students' mathematical questions and curiosities" and "be able to pose good questions and problems that are productive for students' learning" are all three about active engagement with learners' ideas. We have combined these and refer to them as "working with learners' ideas". Secondly, in our data these occurred together within single episodes and separating them was not productive. It is this sixpart analytic framework that we used as an initial analytic frame to study some teaching of probability in relation to critical question (ii) above.

Of course, this orientation to teachers' knowledge has embedded in it a theoretical orientation to teaching and learning, the detail of which is beyond the scope of this paper. Suffice it to say, and as intimated in the discussion of everyday and scientific concepts mentioned above, that we assume here a Vygotskian notion of mathematical teaching/learning as socially mediated (Vygotsky, 1978). Mediating tools and means extend beyond the teacher him or herself, and classroom interaction between teacher and learners, to include the tasks set and the meanings learners bring to class.

\section{Design of the study}

The study has been done in two phases in order to explore all three critical questions, the first phase involved analysis of curriculum documents for secondary school probability in South Africa; curriculum statements, textbooks, public assessments (see Kazima, 2005, for details). The second phase, which is the focus of this paper, was a case study of curriculum in practice. This involved working with and observing a particular mathematics teacher teaching probability. This was in grade 8 at a township secondary school in Johannesburg. Grade 8 was chosen because that is when probability is introduced at secondary schools in South Africa. Township is a context of interest in that it is similar to many schools across towns in Africa, and particularly because we work with teachers in similar contexts. ${ }^{4}$

The teacher was an opportunistic sample, known to the authors, and interested in exploring his own teaching of this new topic. An important point to note here is that the idea was not to evaluate this teacher's teaching but to learn from it, and particularly about the mathematical demands of teaching probability, and in this context. A total of eight lessons were observed and video recorded; copies of all materials produced by the teacher and learners were collected and interviews and discussions with the teacher about the lessons and plans for following lessons were audio recorded.

\section{Teacher's problem solving in grade 8 probability}

Analysis within and across the eight lessons revealed that each of the six aspects of mathematical problem solving by the teacher (defining, explaining, representing, working with learners' ideas, restructuring tasks, and

\footnotetext{
4 The township context was of particular concern and interest to Kazima and her long term work in Malawi where urban schools resemble South African township schools in many ways. Also her own teaching and learning experiences have come from such contexts, and are thus familiar and relatively easy to relate to.
} 
questioning) was evident, but in uneven ways. ${ }^{5}$ In particular, there were many instances of "working with learners' ideas" and "restructuring tasks". This is not surprising. In a pedagogy where learners are invited to engage with a set of tasks, 'working with learners' ideas' and 'restructuring tasks' are both inevitably required of the teacher in the moment. Particularly in the teaching of a relatively new topic, it is difficult for a teacher to predict in advance what ideas learners will offer or how learners will interpret a task. In this case, as we will show, interesting and challenging problem solving was demanded of the teacher as he confronted learners' ideas and the unanticipated unfolding of tasks he had designed.

In the rest of the paper we focus on these two aspects of problem solving, and specifically as these are illuminated by the selected incidents. Our purpose is to illustrate the kind of problem solving that was demanded of the teacher in this case, and what this suggests for the kind of mathematics a teacher might need to know and know how to use MKfT in the teaching of probability at the grade 8 level. As noted earlier, we have reported more fully elsewhere on the extent and prevalence of the different elements of the mathematical work of teaching as revealed in this case.

\section{Restructuring tasks - from rescaling to shifting mathematical outcomes}

Ball et al. (2004) discuss making judgements about mathematical tasks and modifying them accordingly - restructuring of tasks - as an important aspect of mathematical problem solving for teachers. By restructuring, they refer to scaling down of the task if it is too difficult or scaling it up if it is not challenging enough for the learners. In this study we identified another kind of restructuring of tasks that a teacher might need to enact - but here restructuring requires shifting the mathematical outcomes of the task. We illustrate this using an example of a class activity from our study. The teacher gave learners the following task from a textbook. Learners were to do the task in groups.

\footnotetext{
${ }^{5}$ See Kazima and Adler (forthcoming) for a detailed description and analysis of all lessons and the relationship between various mathematical problem solving tasks for the teacher and the knowledge resources drawn on by the teacher in action.
}

Task

1. Flip a coin 30 times and record the number of heads and tails

2. Collect class results in the table on the chalkboard

3. What happens to the number of heads and tails as you add more and more flips?

The teacher's aim (and also the aim of the task in the textbook) was to use this task to illustrate that as the number of trials increase, the better the experimental probability approximates the theoretical probability. In other words, the more the trials the closer the experimental gets to the theoretical probability. For this particular experiment, it was expected that as more and more flips are added the closer the number of heads and tails will get to being equal.

After about 15 minutes of flipping coins, the first group wrote their results in 'after 30 flips' row, the second group added their results to the first group's and filled in the 'after 60 flips' row, the third group added their results to that and filled the 90 flips row, this continued until all nine groups added in their results. Below is the completed table of the class's results.

\begin{tabular}{|c|c|c|}
\hline & H & T \\
\hline After 30 flips & 15 & 15 \\
\hline After 60 flips & 34 & 26 \\
\hline After 90 flips & 48 & 42 \\
\hline After 120 flips & 62 & 58 \\
\hline After 150 flips & 72 & 78 \\
\hline After 180 flips & 89 & 91 \\
\hline After 210 flips & 105 & 105 \\
\hline After 240 flips & 119 & 121 \\
\hline After 270 flips & 131 & 139 \\
\hline
\end{tabular}

Table 1: Table on chalkboard, results from class

Extract 3 is of the discussion that followed. The discussion was in response to the question "what happens as you add more and more flips?" 


\section{Extract 3}

L1: If we add more flips the numbers become more and more

T: What is she saying?

LS: If we add the number become more and more

T: $\quad$ what becomes more

LS: the number that we have

T: another group?

(some noise from learners)

T: please people you are making noise... I want one at a time .. should come here.. I want you to explain what is happening to the frequencies

L2: when we add more flips the numbers increase

$\mathrm{T}: \quad$ is there any group which is saying different other than the numbers become more and more?

L3: in our group we say the ... as we add more and more flips the number is improving

T: what do you mean the number is improving?

L3: it is becoming more

$\mathrm{T}$ : who has something different? I want you to look at the frequencies, what is happening as more flips are added

L4: the number of tails is more different

T: what about the relative frequency? I want you to look at the relative frequencies, what can you say?

(Silence)

Some learners seemed to only notice the numbers increasing; they did not seem to have compared the two columns. Those who compared seemed to think that the more flips you add the more the difference between the total numbers of heads and tails. We will not go into what happened next in that lesson, instead we would like to focus on the problem the teacher needed to solve at this point: the table generated by the task did not visually nor conceptually support the concept of 'law of large numbers' as intended. Restructuring of some kind was needed, in order to continue the lesson. As discussed earlier, Ball et al. (2004) talk of rescaling a task by scaling it up or scaling it down so as to enable learners to engage productively with the task. The restructuring required here is not a scaling up or down. The learners successfully completed the task, and the table set up in the task was appropriately completed by the teacher, with learners in their groups reporting on their throws. The problem for the teacher was that he was presented with results he did not expect and could not use as planned.

So what does he need to know about and for probability, and know how to do it when the activity in which learners are engaged is not able to function as planned i.e. to provide the means to reflect on the law of large numbers? We note that the possibilities we pose here are a result of discussion and reflection on the task and its unfolding. We pursue them to probe the nature of the problem solving needed, and so reflect on the notion of MKfT. We do not pose the obvious question here, though of course this is critical. What would have been a more effective task for the teacher's intended purpose? We engage rather with the situation as it arose - the task was selected from a respected textbook, but as it unfolded, it did not support learners' thinking about the intended mathematical concept.

One possibility is to extend the task (as opposed to rescale) and generate more data so as to provide more possibilities for leading to the intended outcome. How many more would be needed? In a technology supported environment, this might well be an important means to engage the idea, given that generating and recording more throws can be done quickly. What emerged from our reflection, was instead, a different possibility: using the table as is, with the same data, but shifting the outcome from 'law of large numbers' to other possibilities for developing probability concepts that are more visible in the table. For example, concepts such as 'uncertainty', 'randomness', and 'possible outcomes' are all possible concepts to explore by using the data that was generated in the table. The question here is: the data we have does not support the intended probability idea: what else about probability can be explored with or through the table? The failure of the task in relation to its intended outcome, is at the same time an opportunity to explore other relevant ideas and concepts. 


\section{Extract 1 - the unexpected - hearing disconnects}

In the first lesson the teacher asked learners the question: "What is "probability'?", and whether they knew "what probability means". His aim was to find out if the learners had any familiarity with the idea of probability, or if they had used the word before. The extract below captures the discussion that followed in class: $(T=$ teacher, $\mathrm{L}=$ learner, $\mathrm{LS}=$ learners $)$

T: $\quad$ Our deal for the day is to do some mathematics with specific reference to this topic called probability (writes probability on the board) ...I don't know how far are you acquainted with the word probability .... do you know what probability means?

LS: (inaudible)

T: you don't know what it means?

LS: yes

T: okay, anyone who can give me a try ... just give a try ... you are allowed to guess, educational guess is good

(pause, class is quiet)

T: take a guess... what do you think probability could mean?

(points to one boy raising his hand up)

L1: (standing) it is about disabled people

T: it is about?

L1: disabled people

$\mathrm{T}$ : disabled people ..... he says probability is about disabled people. What are you saying (addressing the class) What do you have to say? (points to another boy raising his hand)

L2: (standing) it is about all things we can do

T: $\quad$ it is what?

L2: all things we can do

T: $\quad$ all things we can do

After repeating this learner response, the teacher spends a little more time attempting to elicit further meanings, and then says:

T: okay, so ... other people you don't want to make an attempt ne? and it means you are hearing the word for the very first time ... probability

It is our view that this kind of problem solving for the teacher arises here i.e. in the context of probability, precisely because of the uncertainty of outcomes from probability activities done in class. We thus propose the shifting of appropriate mathematical outcomes as an additional component of restructuring tasks as presented by Ball et al. (2004). Does this happen in other mathematical contexts? Our sense is that it probably does, but perhaps we have not been in a position to notice this kind of potentiality in tasksin-action. In their study of teachers' setting up and implementing mathematical tasks to support reform curricula in the US, Stein, Smith, Henningsen \& Silver (2000) show interesting changes that occur in relation to a task as it comes into use in a classroom setting. Their major finding was the difficulties teachers faced in sustaining high cognitive demand tasks during instruction. In Ball et al.'s (2004) terms, tasks came to be scaled down, both intentionally and unintentionally. Our point here is that in mathematics, some of the work for the teacher includes possibilities for reorienting tasks towards different learning outcomes.

\section{Working with 'expected' and 'unexpected' learners' ideas}

It is now well known that learners bring their own ideas to the classroom. ${ }^{6}$ Some of the learners' ideas can or could be expected by the teacher learning from previous teaching, or from research in the field, or from knowing learners' experiences outside classroom. In such cases teachers could plan in advance how to work with the ideas learners are likely to present. Some learner thinking and ideas, on the other hand, are unexpected. This is an inevitable part of teaching, being as it is a social process. Hence, teachers have to do this kind of problem solving on the spot. We provide two examples from the study, one unexpected and one that perhaps could have been expected. In both cases, particular kinds of mathematical or mathematically related demands were made, and discussion of each provides for an elaboration of MKfT for probability in particular and mathematics in general.

\footnotetext{
${ }^{6}$ See, for example, Brodie \& Pournara (2005) for an insightful analysis of learner centred teaching and research in South Africa.
} 


\section{Mathematical knowledge for teaching: adding to the description \\ through a study of probability in practice}

The problem for the teacher here is that the responses from the learners were both unexpected and unintelligible in his terms. Talking with the teacher after the lesson, and as is apparent from the text, he said he did not expect the responses learners gave, and that he did not know how to make sense of the learners' ideas. He said that he had expected learners to have heard of the word probability, and most likely in the context of weather forecasts. His planning here was that some discussion of the weather would enable him to introduce or link terms like 'certain', 'uncertain', 'likely', etc. The source of the learners' ideas is not the focus of this paper. However, it has particular relevance here, that is a function of learners in this class learning mathematics in English, where this is not their main language. From experience, ${ }^{7}$ we assert that learners who are not first language speakers of English often associate words that sound alike. In this case, the word 'probability' sounds like and so comes to be associated with 'disability' or 'ability'. From this perspective, the two learners' responses of "disabled people" and "all things we can do" are more a function of the sound of the word, than any experience of the use of the word.

On the face of it, an obvious move is to enquire into the strangeness of the learners' responses. In the messiness of classroom life, it is precisely these 'way out' meanings that are deflected or passed over. Yet, in the context of multilingualism, attentiveness to how words sound as well as mean is important. As Adler has argued (2001), different pronounciations, and so sound alike words, can become sources of confusion in mathematics (e.g. size, sides, sights were all used by learners in a trigonometry lesson to refer to the size of an angle). The mathematical work of teaching has linguistic entailments, and the problem solving teachers are required to do on their feet is to pay attention to what is said, how it is said and what could be meant, if they are to enable learners in multilingual settings to work with the language resources they bring to class. This linguistic aspect of problem solving tasks of teaching mathematics is not highlighted in Ball et al.'s (2004) more general framework, and is an important aspect of working with learners' mathematical meaningmaking. In probability, where concepts proliferate, and these are carried in language that is used both mathematically and in the everyday, teachers'

\footnotetext{
7 We draw directly from Kazima's experience in this regard. See Kazima (2006) for a discussion on Malawian learners' meanings of some terms in probability.
}

attention to learners' mathematical meanings needs to include attention to what is being 'sounded' and what these mean for mathematical distinctiveness to develop in language. The example here suggests that the mathematical work of teaching includes listening and hearing disconnects in mathematical terms, and then reconnecting these in mathematical ways.

\section{Exract 2 - the could have been expected - co-existing contradictory concepts}

During Lesson 4 some learners expressed the belief that the number 6 on a die has less chance than each of the other numbers (1-5) of coming uppermost. The lesson started with an activity from a textbook (copied onto a worksheet). Learners in groups were asked to throw a die at least 30 times and record the frequencies of all the six numbers. One of the questions following the activity was "is it more difficult to get a 6 than any other number?" The teacher collected results of each group and displayed these on a chart in form of a table as shown below.

\begin{tabular}{||l|c|c|c|c|c|c|c|}
\hline $\begin{array}{l}\text { Possible } \\
\text { outcomes }\end{array}$ & 1 & 2 & 3 & 4 & 5 & 6 & Total \\
\hline Group 1 & 1 & 5 & 9 & 7 & 4 & 7 & $30^{*}$ \\
\hline Group 2 & 8 & 10 & 5 & 9 & 11 & 7 & 50 \\
\hline Group 3 & 3 & 5 & 0 & 9 & 10 & 3 & 30 \\
\hline Group 4 & 3 & 9 & 5 & 3 & 3 & 7 & 30 \\
\hline Group 5 & 10 & 5 & 11 & 13 & 10 & 10 & 59 \\
\hline
\end{tabular}

Table 2: Chart reflecting die castings

* - we note the error, total should be 33

The discussion which followed is given on the next page.

The teacher's intention was for the learners to reflect on the game they had just played and to use the results collected on the chart to answer the question of whether 6 is more difficult than the other numbers, perhaps to provoke everyday knowledge and intuitions about different numbers and how 'easily' they come up from a die case. As can be seen from the table, total frequency of 6 was 34 out of 202 which was just about the same as the frequency of the numbers 2, 3,4 and 5. The teacher wanted the learners to conclude from this that 6 was just as likely as the other numbers on a die. At first the learners did not seem to pay attention to the game they had played in class, nor to the results but responded by reflecting on their everyday experience. 


\section{Extract 2: discussion}

T: Before we move on ... before we move on with this information which we have on the chart ...with this information which comes from you all, I want you to just respond to this: is it more difficult to get a 6 than any other number? (reading from worksheet). I want your response, what do you say in your group, can you come to a consensus as a group ... the response to that ... is it more difficult to get a 6 than any other number?

L1: yes

T: okay agree in your group.... Agree in your group what do you have to say about that (Learners discussing in groups for about 2 minutes. Learners' talk inaudible on video)

T: What do you say about the answer to that question, is it more difficult to get 6 than any other number? Or do you understand the question?

LS: yes

T: okay, can you make an attempt

L2: yes sir it is difficult to get a 6

T: $\quad$ it is difficult to get a 6

L2: yes

T: okay, what are other groups saying, yes (points to one group)

L3: yes

T: $\quad$ you say yes as well

L3: yes

$\mathrm{T}:$ and that group?

L4: yes

T: $\quad$ now the second question, if you say yes, I want you to explain, why do you say yes? Look at the information you gave here (points to chart on board) look at this information, what does your group say? (pointing to group 3)

L5: we got it three times so it is not difficult to get a 6 ?

T: because you got it?

L5: three times

T: you got it three times?

L5: yes

T: $\quad$ what group are you by the way

L5: group 3

T: you are group 3 ne? (checking on chart on board) you say you got ... therefore it is not difficult to get a 6 ?

L5: yes

T: $\quad$ so you have changed your mind? Before you said yes now you say no is that what group 3 is saying now?

L5: It was not difficult ... we got it three times.. er.. but when we do (inaudible) ... it is difficult.

LS: (inaudible)

T: $\quad$ are you saying when you do it here it is not difficult but when you do it ..er..on your own it is difficult?

LS: yes

$\mathrm{T}$ : what are other people saying?

LS: (inaudible)

T: You know snakes and ladders ne?

LS: yes

T: ludo?

LS: yes

T: hy do you think 6 was chosen for ludo [for the game of ludo, a player is required to get a 6 to start the game]

LS: its difficult

T: No it is not difficult, maybe it was chosen because it is the biggest number I don't know but it is not difficult. 


\section{Mathematical knowledge for teaching: adding to the description through a study of probability in practice}

The learners were assessing the probability of getting a 6 on a die by calling to their minds such instances from past experience. Elsewhere, this has been referred to as the 'availability heuristic' - the use of what is available in one's mind (Tversky \& Kahnemann, 1982). Amir \& Williams (1999), Green (1983) and Watson \& Moritz (2003) all observed that many learners, middle school age, think that the number 6 has less chance of coming up than the other numbers on a die, and that the thinking is influenced by the children's experiences with dice games. Although availability generally is a useful tool, it is also a contradictory tool, as at times what is available (as is the case here) runs counter to the mathematical concept being aimed at. In this context then, what learners bring - what they have available - can lead to misconceptions. In this example, learners recalling dice games and the frustrations of waiting to get a 6 makes the 6 seem less likely than each of the other numbers regardless of the fact that the frequency of the numbers 1-5 were not considered.

The problem for the teacher here, and in our view this is specific to the challenges of teaching probability, is working with learners' everyday knowledge about probability that is at variance with mathematical knowledge. Learning from Laridon's study discussed earlier, learners tend to assimilate their conceptions of probability from experience rather than from their formal learning (Laridon, 1995). In this lesson the teacher collected the results and used a tabular representation so that learners could easily see and compare the frequency of 6 and other numbers. He asked questions while making reference to the chart. He managed to get the learners to use the information to respond to the question. However, the learners seemed to think that 6 was not difficult to get in the classroom but it is difficult to get outside the classroom, for example, when playing ludo where getting a 6 matters.

Others have demonstrated that and how it is possible for learners to hold two contradictory ideas simultaneously. Watson \& Moritz (2003: 272) give examples of learners' statements such as "I know the chance of heads and tails are the same but I always chose tails because it comes up more for me" and "some numbers come up more often, but all dice are fair" (2003: 296). Watson and Moritz conclude that many students hold beliefs that are idiosyncratic and contradictory throughout their years of schooling. This is reminiscent of the finding of Fischbein \& Schnarch, (1997) that children's intuitions about dice do not improve with age.

These contradictions are examples of inconsistency between learners' everyday out-ofclassroom experiences (everyday knowledge) and in-classroom mathematical reasoning (mathematical knowledge). There is a great deal of research and debate on the relationship between everyday and mathematical knowledge in school mathematics classrooms, and we focus on this in more detail elsewhere (Kazima and Adler, forthcoming). The mathematical problem solving demanded of the teacher in this case is first to understand cultural practices and related intuitions that learners have about dice drawn from their everyday experiences. Secondly, in Ball et al.'s (2004) terms, the teacher needs "to be able to interpret and make mathematical and pedagogical judgements" about the learners' ideas, and also to "respond productively" to them. It would clearly be helpful for teachers to know the results of previous research that teaching might not make any difference to learners' intuitions about dice, and this issue was raised earlier in the paper.

So why are we discussing something that is well known? How does it help our thinking about MKfT? The question we posed ourselves here is: what else might a teacher need to do, mathematically, to move on in this situation? This example, and one that might be experienced in other areas of teaching probability, is the mathematical skill of acknowledging learners' intuitions and enabling these to co-exist with increasing experiences of mathematical notions. Asserting the mathematical case can be counterproductive as it could simply be experienced by learners as 'this is what you need to believe in the school mathematics class' rather than providing means for them to continue to engage the contradiction, and so strengthen their understanding. This difficulty gets to the heart of some of the challenges in teaching mathematics in school, where conceptual understanding of an idea appears to be at variance with what learners can engage at particular levels. The temptation for authoritarian assertion, both pedagogically (to move the class on) and mathematically (to make sure a correct mathematical notion is in play) is significant for the teaching. This is a key feature of MKfT, and the on the spot mathematical problem solving a teacher needs to do. It provides a particular content and substance to the broad notion of engaging with learners' thinking, in that it foregrounds the importance of managing both 
everyday and mathematical notions at the same time. This MKfT is different from what might be appropriate with many other mathematical ideas, where key mediational steps might shift learners from their everyday notion to the mathematical notion.

\section{Concluding Discussion}

We have discussed three instances in the teaching of probability in grade 8 in a township (and multilingual) school in South Africa, and brought into focus the kind of mathematical problem solving this teacher faced. The instances discussed were moments of breakdown, and could be viewed negatively. ${ }^{8}$ The value of these instances, in our view, is the 'new' that they made visible to us. Ball et al. (2004) have described working with students' ideas and restructuring tasks as central in the mathematical work of teaching. The instances discussed here elaborate these central tasks in new ways, a function, we would hold, of the mathematical context of probability, a township school, and an experienced teacher teaching a new topic.

The latter two extracts highlighted the mathematical work entailed as teachers work with both expected and unexpected learner ideas. It is almost a tautology to talk about the unexpected in probability, as this is precisely one of its key features. Any pedagogy that sets up games or exploratory tasks related to concepts of probability perhaps need to have as a first expectation, the possibility of the unexpected, indeed the unlikely. These two extracts brought issues of language and everyday knowledge to the fore. Neither is elaborated in Ball et al.'s (2004) framework and suggest a specificity important for teachers to know and be able to act on. On the spot problem solving is needed in multilingual settings when learners are working to understand both new concepts and the language in which these are being presented. A mathematical ear is needed to hear and then engage learner utterances that reflect sound-alike and not only mean-alike ideas. We have called this hearing disconnects. On the spot mathematical problem solving is also needed when learners' cultural knowledge and experience is in contradiction with mathematical knowledge, and these two competing ideas need to co-exist as the latter is strengthened. These are not typical in

\footnotetext{
${ }^{8}$ One reviewer pertinently asked why all three instances were such and why there weren't instances of 'success'. This is an important question in writing about teaching, and one to continually reflect on. Our selection here is precisely because it was in the moments of breakdown that we saw interesting instances of teachers' work.
}

discussion of language and everyday knowledge in mathematics classrooms and so are illuminating of specific challenges teachers can and do face.

Working with activity-based tasks is also not a new issue in our field, but figuring out teachers' mathematical work in this is. Hence our initial focus on the inevitable feature of mathematical problem solving in teaching: restructuring tasks. We have used an example to argue that in some cases, and this is likely in probability tasks, on the spot work might well be about shifting the task so as to work with different mathematical outcomes than those intended. Hence our point that the MKfT notion of restructuring tasks as rescaling is partial. Much more research is needed on tasks and the mathematical work teachers do and need to do as they set up and implement these in and across a range of classroom contexts.

\section{References}

Adler, J. (2001). Teaching mathematics in multilingual classrooms. Dordrecht: Kluwer Academic Publishers.

Adler, J. (2005). Mathematics for teaching: What is it and why do we need to talk about it. Pythagoras, 62, 5-11.

Adler, J. \& Davis, Z. (2006). Opening another black box: Researching mathematics for teaching in mathematics teacher education. Journal for Research in Mathematics Education, 37(4), 270-296.

Amir, G.S., \& Williams, J.S. (1999). Cultural influences on children's probabilistic thinking. Journal of mathematical behaviour, 18(1), 85107.

Ball, D., \& Bass, H. (2000). Interweaving Content and Pedagogy in Teaching and Learning to Teach: Knowing and Using Mathematics. In J. Boaler, (Ed.), Multiple perspectives in mathematics teaching and learning (pp 83-104). Westport: Ablex Publishing.

Ball, D., Bass, H., \& Hill, H. (2004). Knowing and Using Mathematical Knowledge in Teaching: Learning What Matters. In A. Buffgler \& R. Lausch (Eds.), Proceedings of the $12^{\text {th }}$ conference of the Southern African Association for Research in Mathematics Science and Technology Education (pp. 51-65), Durban, South Africa: SAARMSTE.

Ball, D., Lubienski, S., \& Mewborn, D. (2001). Research on teaching mathematics: the unsolved problem of teachers' mathematical knowledge. In V. Richardson, (Ed.), Handbook of research on teaching, 4th ed. (pp 433-456). New York: MacMillan. 


\section{Mathematical knowledge for teaching: adding to the description \\ through a study of probability in practice}

Brodie, K. (2004) Re-thinking teachers' mathematical knowledge: a focus on thinking practices. Perspectives in Education. 22 (1), 6580.

Brodie, K. \& Pournara, C. (2005). Towards a framework for developing and researching groupwork in mathematics classrooms. In R. Vithal, J. Adler \& C. Keitel (Eds.), Researching mathematics education in South Africa (pp 2872). Cape Town: Human Sciences Research Council (HSRC).

Bullough, R. V. Jr. (2001). Pedagogic content knowledge circa 1907-1987: a study in the history of an idea. Teaching and Teacher Education, 17, 655-666.

Canizares, M.J., \& Batanero, C. (1998). A study on the stability of the equiprobability bias in 10-14 year old children. In L. Pereira-Mendoza, L.S. Kea, T.W. Kee \& W. Wong (Eds.), Statistical education: expanding the network (Proceedings of the fifth international conference on teaching statistics) Vol 1 (pp 451-452). Singapore: International Association for Statistical Education.

Department of Education (2001). Revised National Curriculum Statement: Learning Area Statement for Mathematics. Pretoria: Department of Education.

Department of Education (2004). Common Tasks of Assessment: Grade 9. Pretoria: Department of Education.

Even, R. (1990). Subject matter knowledge for teaching and the case of functions. Educational studies in mathematics, 21(6), 521-544.

Ferrini-Mundy, J., Senk, S., \& McCrory, R. (2005). Measuring Secondary School Mathematics Teachers' Knowledge of Mathematics for Teaching: Issues of Conceptualization and Design. ICMI Study Group 15 Águas de Lindóia, Brazil - May. Retrieved May 20, 2006, from www.msu.edu/\%7Ekat/icmi.htm

Fischbein, E., \& Gazit, A. (1984). Does the teaching of probability improve probabilistic intuitions? An exploratory research study. Educational studies in mathematics, 15, 1-24.

Fischbein, E., Nello, M., \& Marino, M. (1991). Factors affecting probabilistic judgements in children and adolescents. Educational studies in mathematics, 22(6), 523-549.

Fischbein, E., \& Schnarch, D. (1997). The evolution with age of probabilistic, intuitively based misconceptions. Journal for research in mathematics education, 28, 96-105.
Green, D.R. (1983). Shaking a six. Mathematics in school, 12(5), 29-32.

Green, D.R. (1989). School pupils' understanding of randomness. In R. Morris (Ed.), Studies in Mathematics Education: Vol, 7. The teaching of statistics (pp 27-39). Paris: UNESCO.

Hill, H.C., \& Ball, D. L. (2004). Learning mathematics for teaching: Results from California's mathematics professional development institutes Journal for Research in Mathematics Education, 35 (5), 330-351.

Kazima, M. (2005). Mathematical knowledge for teaching probability in secondary schools: a research proposal. In C. Kasanda, L. Muhammed, S. Akpo and E. Ngololo (Eds.), Proceedings of the $13^{\text {th }}$ conference of the Southern Africa Association of Mathematics Science and Technology Education (SAARMSTE), (pp 332-336),. 10-15 January 2005, Windhoek, Namibia.

Kazima, M. (2006). Malawian students' meanings for probability vocabulary. To appear in Educational studies in mathematics, special issue on multilingualism

Kazima, M., \& Adler, J. (forthcoming). Everyday knowledge as resource and obstacle in teaching of probability.

Kvatinsky, T., \& Even, R. (2002). Framework for teacher knowledge and understanding of probability. In B. Phillips (Ed.), Proceedings of the sixth international conference on the teaching of statistics, (On CD), Hawthorn, VIC: International Statistical Institute.

Laridon, P. (1995). Intuitive probability concepts in South African adolescents. Pythagoras, 37, 25-29.

Lecoutre, M. (1992). Cognitive models and problem spaces in purely random situations. Educational studies in mathematics, 23(6), 557568.

Li, J. \& Pereira-Mendoza, L. (2002). Misconceptions in probability. In B. Phillips (Ed.), Proceedings of the sixth international conference on the teaching of statistics, (On CD), Hawthorn, VIC: International Statistical Institute.

Ma, L. (1999). Knowing and Teaching elementary mathematics: teachers' understanding of fundamental mathematics in China and the United States. New Jersey: Lawrence Erlbaum.

Margolinas, C., Coulange, L., \& Bessot, A. (2005). What can the teacher learn in the classroom? Educational studies in mathematics, 59, 205234. 
Marks, R. (1992). Pedagogical content knowledge: from a mathematical case to a modified conception. Journal of teacher education, 4(3), 3-11.

Pillay, V. (2006). An investigation into mathematics for teaching: the kind of mathematical problem-solving a teacher does as he/she goes about his/her work. Unpublished M Sc Ed research report. Johannesburg: University of the Witwatersrand

Pimm, D. (1987) Speaking Mathematically: Communication in Mathematics Classrooms. London: Routledge \& Kegan Paul.

Saenz, C. (1998). Teaching probability for conceptual change. Educational studies in mathematics, 35, 233-254.

Saljo, R., \& Wyndhamn, J. (1993). Solving everyday problems in the formal setting: an empirical study of the school as context for thought. In S. Chaiklin, \& J. Lave (Eds.), Understanding practice (pp327-343). New York. Cambridge University Press.

Sanchez, V., \& Llinares, S. (2003). Four student teachers' pedagogical reasoning on functions. Journal of mathematics teacher education, 6, 525.

Shulman, L. S. (1986). Those who understand: knowledge growth in teaching, Educational researchers, 15(2), 4-14.
Shulman, L. S. (1987). Knowledge and teaching: foundations of the new reform. Harvard educational review, 57(1), 1-22.

Stacey, K., Helme, S., Steinle, V., Baturo, A., Irwin, K., \& Bana, J. (2003). Preservice teachers' knowledge of difficulties in decimal numeration. Journal of mathematics teacher education, 4, 205-225.

Stein, M., Smith, M., Henningsen, M., \& Silver, E. (2000). Implementing standards-based mathematics instruction: A casebook for professional development. . Reston: NCTM.

Tversky, A., \& Kahnemann, D. (1982). Availability: a heuristic for judging frequency and probability. In D. Kahnemann, P. Slovic, \& A. Tversky (Eds.), Judgement under uncertainty: heuristics and biases (pp 163-178). Cambridge: Cambridge University Press.

Vygotsky, L.S. (1978). Mind in Society. Cambridge: Harvard University.

Watson, J.M., \& Moritz, J.B. (2003). Fairness of dice: a longitudinal study of students' beliefs and strategies for making judgements. Journal for research in mathematics education, 34, 270304.

Watson, J.M. (2005). The probabilistic reasoning of middle school students. In G.A. Jones (Ed.), Exploring probability in school: challenges for teaching and learning (pp 145-170). New York: Springer.

"I think you're begging the question," said Haydock, "and I can see looming ahead one of those terrible exercises in probability where six men have white hats and six men have black hats and you have to work it out by mathematics how likely it is that the hats will get mixed up and in what proportion. If you start thinking about things like that, you would go round the bend. Let me assure you of that!"

\section{- Agatha Christie}

